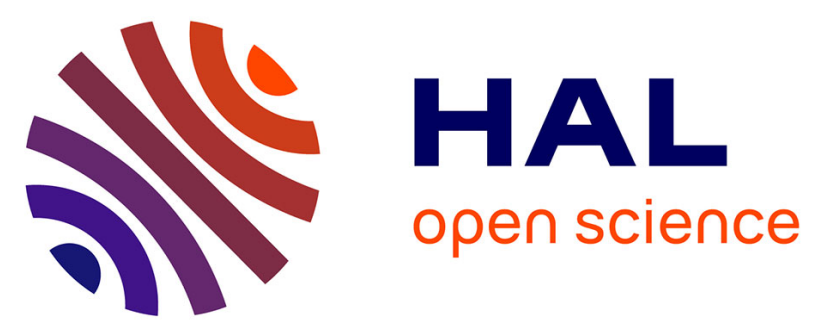

\title{
Crystal plasticity modeling of the effects of crystal orientation and grain-to-grain interactions on DSA-induced strain localization in Al-Li alloys
}

Satyapriya Gupta, Vincent Taupin, Claude Fressengeas, Juliette Chevy

\section{To cite this version:}

Satyapriya Gupta, Vincent Taupin, Claude Fressengeas, Juliette Chevy. Crystal plasticity modeling of the effects of crystal orientation and grain-to-grain interactions on DSA-induced strain localization in Al-Li alloys. Materialia, 2019, 8, pp.100467. 10.1016/j.mtla.2019.100467 . hal-02351519

\author{
HAL Id: hal-02351519 \\ https://hal.science/hal-02351519
}

Submitted on 14 Nov 2019

HAL is a multi-disciplinary open access archive for the deposit and dissemination of scientific research documents, whether they are published or not. The documents may come from teaching and research institutions in France or abroad, or from public or private research centers.
L'archive ouverte pluridisciplinaire HAL, est destinée au dépôt et à la diffusion de documents scientifiques de niveau recherche, publiés ou non, émanant des établissements d'enseignement et de recherche français ou étrangers, des laboratoires publics ou privés. 


\title{
Crystal plasticity modeling of the effects of crystal orientation and
} grain-to-grain interactions on DSA-induced strain localization in Al-Li alloys

\author{
Satyapriya Gupta ${ }^{\mathrm{a}, \mathrm{b}, *}$, Vincent Taupin ${ }^{\mathrm{a}, \mathrm{b}}$, Claude Fressengeas ${ }^{\mathrm{a}, \mathrm{b}}$, Juliette Chevy $^{\mathrm{c}}$ \\ ${ }^{a}$ Laboratoire d'Etude des Microstructures et de Mécanique des Matériaux, \\ LEM3, Université de Lorraine/CNRS/Arts et Métiers ParisTech \\ 7 rue Félix Savart, 57070 Metz, France \\ ${ }^{b}$ Laboratory of Excellence on Design of Alloy Metals for low-mAss Structures (DAMAS) \\ Université de Lorraine, Nancy-Metz, France \\ ${ }^{c}$ C-TEC Constellium Technology Center, 725 Rue Aristide Bergès, Voreppe 38341 cedex, France
}

\begin{abstract}
We develop a crystal plasticity model to investigate the coupled actions of crystal orientation, grain neighborhood and grain-to-grain elasto-plastic interactions on dynamic strain aging (DSA) and the onset and development of associated plastic strain localization in Al-Li alloys. Considering simple model multilayered microstructures with preferred orientations representative of rolled alloys, the aim is to identify grain orientation couples that can limit dynamic strain aging induced strain localization without compromising the flow stress and strain hardening properties. To this end, a slip system-based formulation of dynamic strain aging is implemented in a crystal plasticity finite element framework. The model validity is first checked with the simulation of a tensile specimen loaded at quasi-static applied strain rate. The introduction of dynamic strain aging allows predicting complex propagation of intense plastic localization bands. We further investigate the influence of crystal orientations on early strain localization in $\mathrm{Al}-\mathrm{Cu}-\mathrm{Li}-\mathrm{Mg}$ alloys, by performing simulations representative of the early stage of a Kahn Tear test for single crystals and layered polycrystals. Using experimentally reported crystal orientations for rolled microstructures, the simulation results show that in both single and multilayered crystals, there is a strong influence of dynamic strain aging on localization patterns, as well as a significant orientation dependence. In multilayered crystals, the nature of strain localization can be remarkably modified when stand-alone crystals of a certain orientation are coupled with other orientations: strain localization may intensify or fades away depending on the coupling with neighboring orientations.
\end{abstract}

Keywords: Dynamic strain aging; Al-Li alloys; strain localization; grain orientation; crystal plasticity finite element modeling.

\section{Introduction}

This paper focuses on early plastic strain localization issues in $\mathrm{Al}-\mathrm{Cu}-\mathrm{Li}-\mathrm{Mg}$ alloys used as light weight material solutions in the aerospace industry where the primary challenge is to reduce the overall weight of the aircrafts for enhanced fuel efficiency and reduced carbon emission [1-4]. In addition to their low density, these alloys offer an excellent resistance to corrosion and a combination of weldability, mechanical strength and damage tolerance not achieved in conventional alloys [5/7]. However, strain localization phenomena occurring in these alloys which can result into reduced toughness, and the limited understanding of

${ }^{*}$ Correspondence: guptas15@msu.edu; Tel +15174889302

Email addresses: guptas15@msu.edu (Satyapriya Gupta), vincent.taupin@univ-lorraine.fr (Vincent Taupin), claude.fressengeas@univ-lorraine.fr (Claude Fressengeas), juliette.chevy@constellium.com (Juliette Chevy) 
the complex relationships between localization, damage and material properties such as solute/precipitate hardening/softening and crystallographic/morphological texture, still hamper their widespread usage [8 10]. Extensive experimental and theoretical efforts have been made in the recent past for a better understanding of these relationships [11-15].

In this work, focus is placed on the role of solute strengthening and dynamic strain aging (DSA) induced Portevin-Le Chatelier (PLC) effect, which is thought to be the primary phenomena responsible for plastic strain localization in such alloys. In general, PLC effect is manifested as serrated stress-strain curve and visible strain localizations in the form of inclined deformation bands and caused by repeated interaction between the moving dislocations and diffusing solute atoms in dilute $\mathrm{Al}$ alloys. Although, in contrast to PLC effect, some precipitates, such as so-called T1 precipitates present in the AA-2198-T8 alloy, were experimentally suggested to favor homogenization of plastic deformation [16-19], the effect of precipitation is not considered here and it is left for a forthcoming study. Few experimental studies explored the role of DSA in the early strain localization processes leading to failure [20 24], and even fewer discussed the issue in $\mathrm{Al}-\mathrm{Cu}-\mathrm{Li}-\mathrm{Mg}$ type alloys [25, 13, 26, 27]. Although such alloys usually do not display the typical serrated stress-strain curves commonly observed in monotonic uniaxial tensile loading of conventional $\mathrm{Al}-\mathrm{Mg}$ alloys, recent experimental observations in the AA2024 and AA2139 alloys [28, 29] suggested that DSA could be activated during interrupted tensile tests, or after jumps in the loading strain rate. Thus, DSA cannot be ignored in complex forming operations, despite possibly evanescent manifestations in monotonic loading. Recent in-situ experimental studies combining X-ray laminography and 3D digital image correlation methods during Kahn tear tests on a AA-2198-T8 rolled material, and on other similar alloys, clearly evidenced the occurrence of early plastic strain localization [13, 30]. It was observed that intense plastic localization bands form away from the crack tip at the very beginning of deformation, and these bands are intermittent in time but not in space. This is very detrimental as plastic deformation will accumulate in bands, which inevitably leads to fracture of the specimens due to progressive void nucleation and coalescence at intermetallic particles in these slanted bands. By performing Kahn tear tests simulations using a finite element model that couples crystal plasticity, dynamic strain aging, damage and fracture, it was affirmative that dynamic strain aging is responsible for these early strain localization phenomena [26]. Localization bands intermittent in time but less in space were indeed predicted in good agreement with experimental data, which lead to damage and eventual fracture of the samples.

Motivated by the above studies [13, 30, 26], present work contributes to further investigation in terms of modeling the role of crystal orientations, plastic anisotropy, grain neighborhood, and grain-to-grain interactions on the intensity of dynamic strain aging effects. In a recent study, simple model lamellar grain structures representative of rolled microstructures were modeled, using experimentally reported preferred crystal orientations [31. Plastic heterogeneity and anisotropy was observed in the simulations. Such anisotropy and a significant soft-stiff grain-to-grain contrast was further reported both experimentally and theoretically in similar Al-Li rolled alloys [32 34, where in particular Brass and S orientations exhibit a strong stiff-soft behavior contrast. As such, with the eventual aim of minimizing or avoiding the detrimental effects of DSA on strain localization and the subsequent fracture process of $\mathrm{Al}-\mathrm{Cu}-\mathrm{Li}-\mathrm{Mg}$ alloys through adequate material design, we strive to understand how DSA interacts with typical crystallographic and morphological orientation patterns. In the present work, we probe these interactions using a crystal plasticity finite element (CPFE) model. For capturing the key features of these interactions, a slip system-based dynamic strain aging module is added to the modeling framework. In studying the roles of grain morphology and orientation on strain localization, experimentally observed layered microstructures and dominant crystal orientations are employed. More precisely, we will perform simulations representative of the early stage deformation of a Kahn tear test, considering first, single 
Table 1: Grain orientations used in the simulations. The Euler angles $\left(\phi_{1}, \phi, \phi_{2}\right)\left(\right.$ in $\left.^{\circ}\right)$ provide the orientation of the crystal with respect to the rolling frame.

\begin{tabular}{cccc} 
Orientation & $\phi 1$ & $\phi$ & $\phi_{2}$ \\
\hline Brass-b & 35.26 & 45.0 & 0.0 \\
\hline S-d & -121.02 & 143.3 & 26.57 \\
\hline Cube & 0.0 & 0.0 & 0.0 \\
\hline Goss & 0.0 & 45.0 & 0.0 \\
\hline TCX & 72.9 & 22.6 & 36.9 \\
\hline
\end{tabular}

crystals and specific orientations (see Table1). In particular we have considered a variant of the Brass texture component (called Brass-b hereafter), a variant of the $\mathrm{S}$ texture component (presented as S-d hereafter), Cube and Goss texture components, as well as an unknown texture component X (will be called TCX hereafter).

As we neglect precipitation here, the material modeled can be considered as a AA-2198T3 type alloy instead of the AA-2198-T8 alloy, where strong nanosize precipitates have been formed during additional aging. The aim is not to fit as close as possible available experimental curves here, but rather to identify which orientations are better in terms of limiting plastic strain localization initiating at the crack tip and very quickly propagating through the material and in terms of flow stress and strain hardening. Second, based on lamellar structures typical of 2198 , we will simulate the same test for model microstructures with two major grain orientations, for instance, stacks of alternate Brass-b and S-d lamellar grains will be modeled and simulated. This study tries to be useful in terms of materials design as it allows probing the effect of coupling a given orientation with other neighboring orientations on the plastic heterogeneity and anisotropy.

The following sections of the paper are therefore organized as follows. The small strain crystal plasticity framework accounting for DSA is presented in Section 2. Proper working of the DSA-embedded CPFE model is numerically validated in Section 3. CPFE simulation results obtained for different crystal orientations and several layered morphologies of orientation couples are presented and discussed in Section 4 . Finally, conclusions of the work are listed in Section 5 .

\section{DSA-enabled CPFE model}

The unknown field is the displacement field $\mathbf{u}$ in a body $B$ subjected to displacement and/or traction boundary conditions. In the absence of inertial and body forces, the momentum balance equation and boundary conditions can be written as

$$
\begin{aligned}
\operatorname{div} \mathbf{T} & =0, \\
\mathbf{T} \cdot \mathbf{n} & =\overline{\mathbf{t}} \text { on } S_{t}, \\
\mathbf{u} & =\overline{\mathbf{u}} \text { on } S_{u},
\end{aligned}
$$

where $\mathbf{T}$ is the stress tensor and $(\overline{\mathbf{t}}, \overline{\mathbf{u}})$ are prescribed tractions and displacements at external boundaries of unit normal $\mathbf{n}$, respectively. Homogeneous linear isotropic elasticity of the material is assumed:

$$
T_{i j}=\lambda \epsilon_{k k}^{e} \delta_{i j}+2 \mu \epsilon_{i j}^{e} .
$$

In this relation, $\lambda$ and $\mu$ are the Lamé constants, and $\boldsymbol{\epsilon}^{e}$ the elastic strain tensor. In a small strain setting, $\boldsymbol{\epsilon}^{e}=\boldsymbol{\epsilon}-\boldsymbol{\epsilon}^{p}$, where $\boldsymbol{\epsilon}$ and $\boldsymbol{\epsilon}^{p}$ are the total and plastic strain tensors. 


\subsection{Crystal plasticity module}

In the present crystal plasticity model, we follow the formulation used for aluminium crystals in [35. The plastic velocity gradient $\mathbf{L}_{p}$ (whose symmetric part is the plastic strain rate tensor $\dot{\boldsymbol{\epsilon}}^{p}$ ) is obtained in a classical manner from the summation of the shear rates arising from dislocation glide on all activated slip systems:

$$
\mathbf{L}_{p}=\sum_{s} \dot{\gamma}_{s} \mathbf{P}_{s}=\sum_{s} \rho_{s}^{m} b v_{s} \mathbf{m}_{s} \otimes \mathbf{n}_{s} .
$$

In this relation, $\mathbf{P}_{s}=\mathbf{m}_{s} \otimes \mathbf{n}_{s}$ is known as the orientation Schmid tensor of the slip system $s$ with slip direction $\mathbf{m}_{s}$ and unit normal $\mathbf{n}_{s}$. The shear rate $\dot{\gamma}_{s}$ on the slip system $s$ is given by the Orowan relationship $\dot{\gamma}_{s}=\rho_{s}^{m} b v_{s}$, where $b$ is the magnitude of the Burgers vector on all slip systems, $\rho_{s}^{m}$ denotes the mobile dislocation density and $v_{s}$ is the dislocation velocity on slip system $s$. The plastic slip on system $s$ is driven by the resolved shear stress $\tau_{s}=\mathbf{T}: \mathbf{P}_{s}$ through the power law relationship

$$
v_{s}=v_{0}\left(\frac{\left|\tau_{s}\right|}{\tau_{s}^{h}+\tau_{s}^{\text {sol }}}\right)^{n} \operatorname{sgn}\left(\tau_{s}\right)
$$

reflecting hardening from thermally activated obstacle overcoming, where $v_{0}$ is a reference velocity and $n$ a power law exponent. The stress $\tau_{s}^{h}$ reflects forest hardening on the slip system $s$, and is assumed to be of the following form:

$$
\tau_{s}^{h}=\mu b \sqrt{\sum_{j} a_{j s} \rho_{j}^{f}},
$$

where $a_{j s}$ is a latent hardening coefficient providing the contribution of the dislocation forest density $\rho_{j}^{f}$ on system $j$ to the hardening of system $s\left[36\right.$. A mean value $a_{\text {mean }}$ will be taken for all these coefficients, except for the collinear interactions where the (larger) value $a_{c o l}$ will be used. In the provisional absence of DSA, the rates of change of the mobile $\rho_{s}^{m}$ and forest $\rho_{s}^{f}$ dislocation densities on slip system $s$ are taken as

$$
\begin{aligned}
\frac{\dot{\rho}_{s}^{m}}{\rho_{0}^{m}} & =\left(K_{m}-K_{f}+\frac{C_{1}}{\sqrt{\rho_{0}^{m}}} \sum_{j} \sqrt{\rho_{j}^{f}}-\frac{C_{2}}{\rho_{0}^{m}} \sum_{j} \sqrt{\rho_{s}^{m} \rho_{j}^{f}}\right)\left|\dot{\gamma}_{s}\right|, \\
\frac{\dot{\rho}_{s}^{f}}{\rho_{0}^{m}} & =\left(K_{f}+\frac{C_{2}}{\rho_{0}^{m}} \sum_{j} \sqrt{\rho_{s}^{m} \rho_{j}^{f}}-\frac{C_{3}}{\rho_{0}^{m}} \rho_{s}^{f}\right)\left|\dot{\gamma}_{s}\right| .
\end{aligned}
$$

In the above, $K_{m}$ is connected with the multiplication and $K_{f}$ with the immobilization of mobile dislocations on obstacles initially present in the crystal. $C_{1}$ reflects the contribution of the forest dislocations to mobile dislocation sources. $C_{2}$ accounts for the immobilization of mobile dislocations due to their interactions with the forest. $C_{3}$ stands for dynamic recovery. $\rho_{0}^{m}$ is a reference dislocation density value. By handling separately the dislocation densities on each slip system, these evolution laws are designed to account for the effects of crystal orientation on the flow stress and work hardening rate [35]. In addition, Eq. (8) is meant to reflect the quick increase and saturation of the mobile dislocation density on an activated slip system.

\subsection{Dynamic strain aging module}

In Eq.(6), $\tau_{s}^{s o l}$ is an additional hardening stress arising from DSA, i.e., from recurrent pinning by diffusing solute atoms and eventual breakaway of mobile dislocations arrested on their obstacles. Its evolution with the aging time of arrested dislocations and the solute 
In Eqs. (1011), the effects of DSA on the time evolution of the dislocation densities are taken into account through the terms involving $A_{1}$, as they effectively integrate the dynamics of dislocations and solute atoms. These terms control the exchange of dislocations between $\rho_{s}^{m}$ and $\rho_{s}^{f}$ by arrest and breakaway of mobile dislocations in relation with solute diffusion. The characteristic time $t_{s}^{l}$ (also called loading time) are defined from the elementary incremental strain $\Omega_{s}$ and the overall loading strain rate $\dot{\epsilon}_{a}$ :

$$
t_{s}^{l}=\frac{\Omega_{s}}{\dot{\epsilon}_{a}}=\frac{b \bar{\rho}_{s}^{m} / \sqrt{\bar{\rho}_{s}^{f}}}{\dot{\epsilon}_{a}} .
$$

The incremental strains $\Omega_{s}$ depend only on the slow time scale evolutions of $\rho_{s}^{m}$ and $\rho_{s}^{f}$, as determined from Eqs. 890 and denoted $\left(\bar{\rho}_{s}^{m}, \bar{\rho}_{s}^{f}\right)$, but the characteristic times $t_{s}^{l}$ set the time scales for the fast dislocation dynamics associated with DSA. $p\left(\dot{\gamma}_{s}\right)$ represents the probability density for dislocations to get pinned at obstacles by clouds of solute atoms on slip system $s$. Expressed in terms of the plastic strain rate $\dot{\gamma}_{s}$, it reflects the elastic dislocation-solute interactions on slip system $s$ and can be taken as

$$
p\left(\dot{\gamma}_{s}\right)=\frac{2 \dot{\gamma}_{s}}{\dot{\epsilon}_{0}^{2}} \exp \left(-\left(\dot{\gamma}_{s} / \dot{\epsilon}_{0}\right)^{2}\right) .
$$

where the reference strain rate $\dot{\epsilon_{0}}$ is an input parameter regulating the type of serration achieved from the model. In the presence of DSA, a switch occurs repeatedly between low and high solute concentration $C_{s}^{s o l}$ along the master curve described in Eq. 14 as a function of the dislocation aging time $t_{s}^{a}$.

$$
C_{s}^{s o l}=1-\exp \left(-\left(\frac{t_{s}^{a}}{t_{D}}\right)^{2 / 3}\right)
$$

In relation (14), $t_{D}$ is a time scale characterizing solute diffusion. The switch is therefore controlled by the aging time, which in turn primarily depends on the magnitude of the local plastic strain rate $\dot{\gamma}_{s}$. In the model [37], this switch is achieved through a relaxation process, according to which the aging time $t_{s}^{a}$ follows the waiting time $t_{s}^{w}$ (mobile dislocations wait on their obstacles in slip system $s$ ) with some delay:

$$
\begin{aligned}
\frac{d t_{s}^{a}}{d t} & =1-\frac{t_{s}^{a}}{t_{s}^{w}} \\
t_{s}^{w} & =\frac{\Omega_{s}}{\left|\dot{\gamma}_{s}\right|} .
\end{aligned}
$$


Hence, the PLC instability occurs when the waiting time $t_{s}^{w}$, which indirectly depends on the flow stress, drops down to zero, reflecting the unpinning of dislocations from solute atmospheres. The solute-related resistance $\tau_{s}^{\text {sol }}$ on slip system $s$ is now taken as the product of the solute concentration $C_{s}^{s o l}$ on arrested dislocations and a saturation stress level $f$ reached at large aging times $t_{s}^{a}$ :

$$
\tau_{s}^{s o l}=f C_{s}^{s o l} .
$$

Note that all the CP and DSA material parameters are listed in Table 2. The parameters for DSA and latent hardening are taken from previous works [38, 37, 35].

\subsection{Numerical strategy}

The standard Galerkin finite element method is used for the spatial discretization and numerical solution of the problem set out be Eqs.(3) through (17). Note that the differential equations and relations (10,17) presented above constitute a stiff differential system involving fast variables undergoing large changes in a small amount of time. An explicit time-marching scheme is employed with sufficiently small time steps, to ensure numerical stability of the solution. The choice of time step $\Delta t$ is chosen based on limited relative evolution of both $\mathbf{L}_{p}$, $t_{s}^{a}$ and $\dot{\gamma}_{s}$ quantities. The model is implemented in the framework provided by Freefem ++ , a free software based on the finite element method having a high level integrated development environment for the numerical solution of partial differential equations in two or three dimensions [39].

\section{DSA endorsed strain localization in single crystal tension: validation of model}

Single crystal stretching simulations are performed using the above described DSAenabled model to examine the proper working, capabilities and flexibility of the CPFE code. The simulation results are compared with conventional CP response to highlight the influence of DSA on the mechanical response. A classical dog bone-shaped sample is simulated with uniaxial tension velocity driven boundary conditions in the $\mathrm{X}$ direction. Note that $\mathrm{X}, \mathrm{Y}, \mathrm{Z}$ in FE model correspond to RD,TD and ND. The FE domain (generated by the mesh module of Freefem ++ ) is discretized with cubes composed of tetrahedral elements and the crystal lattice is assigned Euler angles characteristic of the cubic orientation, typically close to experimentally used orientations in tensile samples. The material properties and initial condition parameters used for the simulations are listed in Table 2. The applied strain rate is $10^{-4} / \mathrm{s}$. In all forthcoming simulations, the mesh is chosen fine enough such that realistic plastic localization bands can develop. However, in a more realistic setup, one should consider strain gradient plasticity or field dislocation mechanics [40] approaches, where a characteristic internal length scale related to width of localization bands can be explicitly or inherently introduced to removes any mesh size dependence of the plastic bands [41]. In our simulations, there is no physical size introduced, only the effect of grain morphologies, its distribution and the ratio of lamellar grain thicknesses in our multilayered simulations is important.

Two different regimes of plastic activity were observed. Fig.1(a) shows a zoomed-in view of the macroscopic stress-strain curve obtained from the DSA-enabled model featuring a sequence of irregular events, which can be compared with the very smooth curves obtained from conventional CP modeling in Fig.1(b), The magnitude of the stress serrations is very small (which is realistic for $\mathrm{Al}-\mathrm{Cu}-\mathrm{Li}-\mathrm{Mg}$ alloys) for the adopted DSA parameters. In addition, a higher flow stress (an increase of the yield stress of about $50 \mathrm{MPa}$ ) together with larger yield drop is observed for DSA-enabled model as compared to the conventional CP model. This is due to the fact that, in the latter case, the yield point originates in a burst of the mobile dislocation density (due to very small initial mobile dislocation densities $\rho_{s}^{m}(0)$ ), 


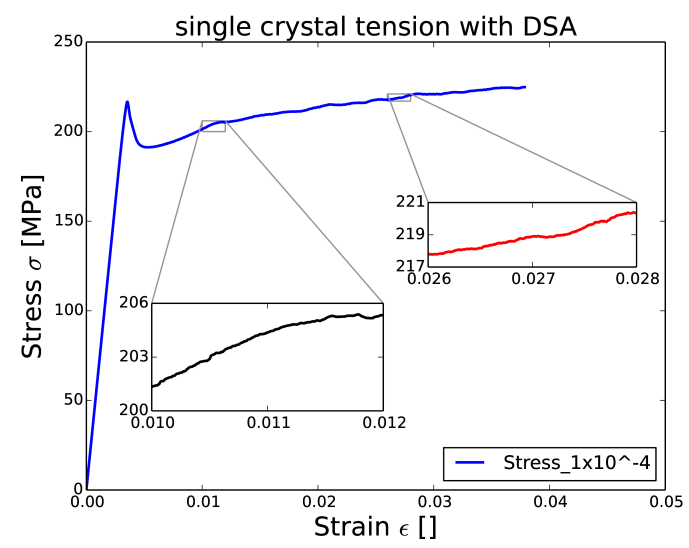

(a)

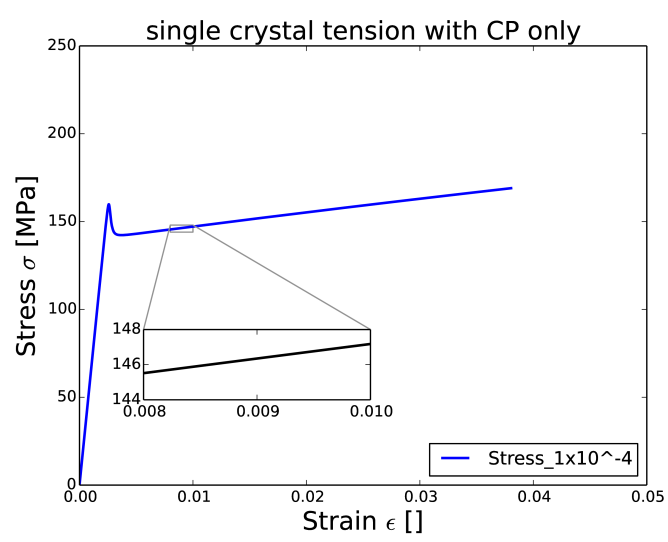

(b)

Figure 1: Macroscopic deformation behavior of dogbone-shaped single crystal in tension, (a) with DSA enabled crystal plasticity; (b) In the absence of DSA (crystal plasticity only).

The simulation results are also analyzed at a more local level using the longitudinal strain rate fields (primarily plastic strain rate) obtained from both the DSA-enabled CP and conventional CP models. The dogbone shape of the simulated sample provides natural opportunity for stress concentration at the shoulders, and thereby a region to initiate strain localization. As shown in Fig.2(a), nucleation, motion and intermittency of strain localization in the form of bands can be observed in the DSA-enabled model. For instance, a closer look on the maps at time steps (ts) 190,250, and 300 demonstrates the formation of two new bands at the specimen shoulders and disappearance of the band in the middle of the mesh. The manifestations of these plastic instability events are clearly the attributes of repeated collective pinning and breakaway of mobile dislocations.

On the contrary, strain localization is completely absent from the strain rate fields obtained from the conventional CP model (see Fig. 2(b)), which confirms the proper working of the DSA-enabled model and also highlights the influence of DSA on the local deformation behavior of the material. We indeed observe a very homogeneous strain rate field throughout the gauge length of the specimen in Fig. 2(b). The initial burst of mobile dislocations due to low initial mobile dislocation densities $\rho_{s}^{m}(0)$ is seen to temporarily fill up the gauge length with high strain rate.

\section{Strain localization in $\mathrm{Al}-\mathrm{Cu}-\mathrm{Li}-\mathrm{Mg}$ alloys: Influence of crystal orientation and morphological texture}

As already mentioned, the present study is grounded on the presumption that strain localization is a middle link of deformation and ultimate fracture. Strain localization is therefore the primary focus of our investigation. The following study is conducted to investigate how the crystal orientation and layered morphology can influence the strain localization process ahead and away from a crack tip in the presence of DSA. In the bigger picture, this investigation aims at tailoring a textured alloy, in order to make it less susceptible to strain localization and thus to have better damage/fracture resistance.

\subsection{Edge cracked single crystal: effect of crystal orientation}

The simulation results presented in the previous section demonstrate that DSA can trigger plastic instabilities in dilute $\mathrm{Al}$ alloys, which are otherwise absent when DSA is omitted. 


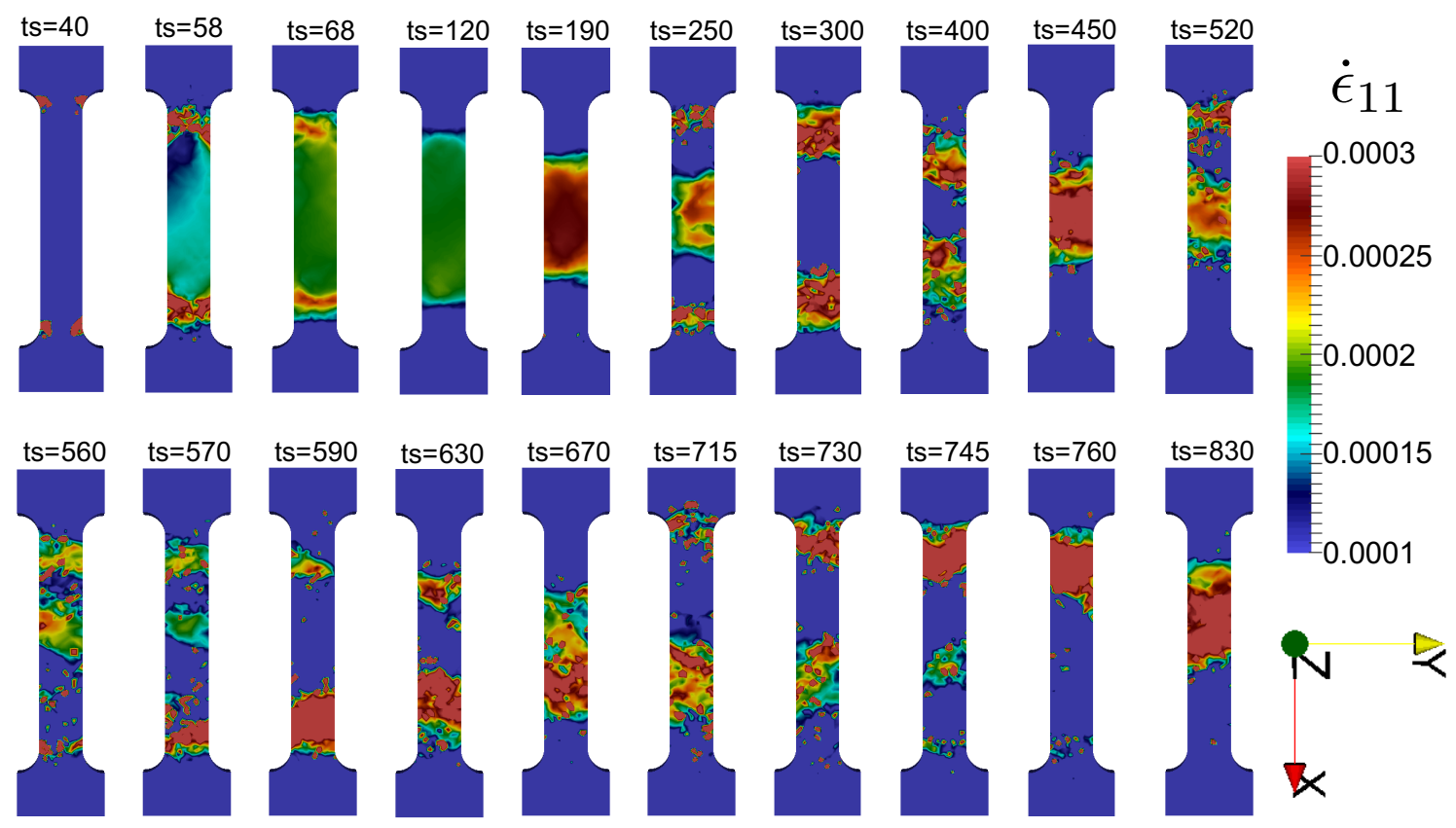

(a)

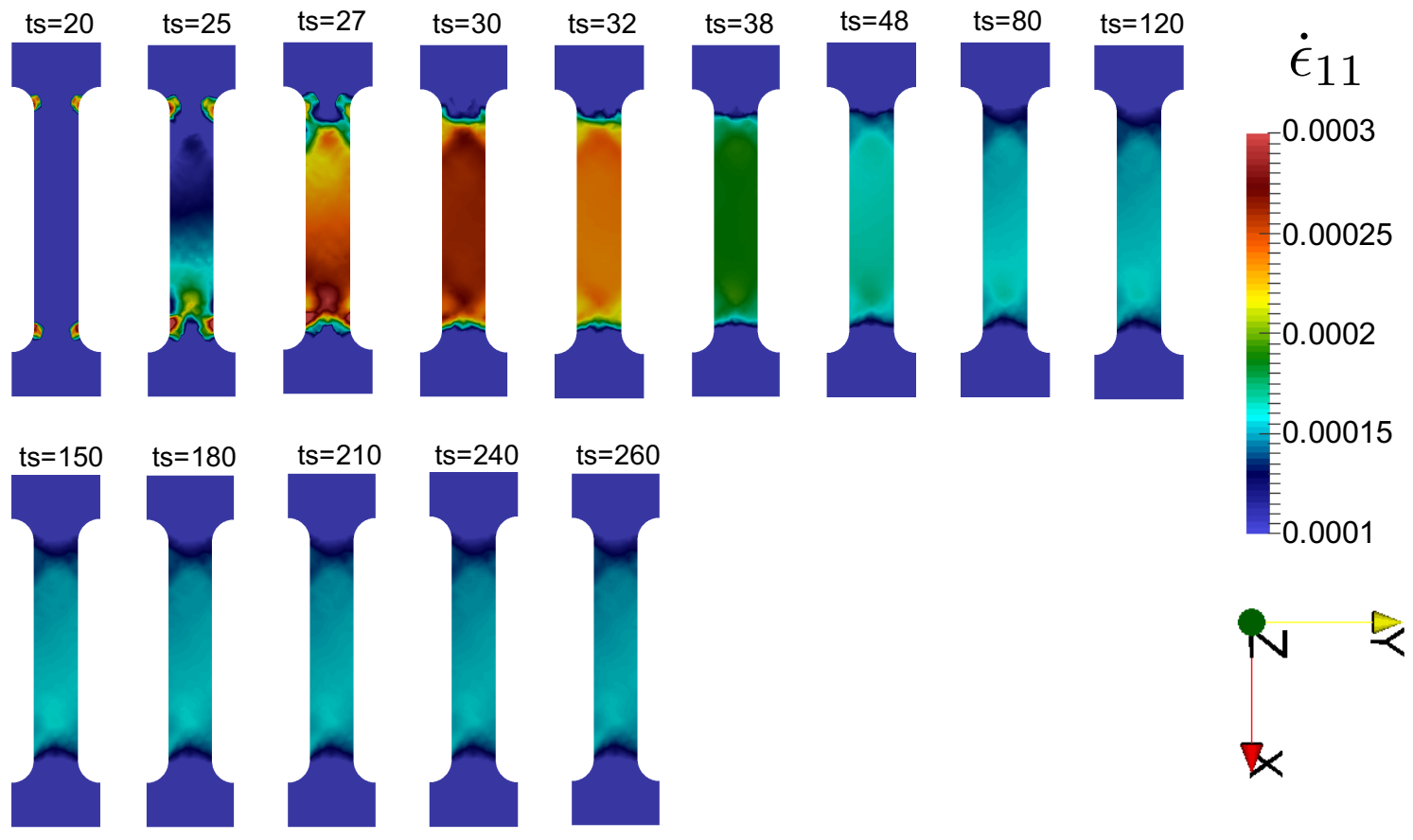

(b)

Figure 2: Longitudinal strain rate field $\dot{\epsilon}_{11}$ at gradually increasing simulation time steps for the dog boneshaped single crystal (a) simulated with DSA enabled crystal plasticity where destabilizing influence of DSA is manifested in the form of the nucleation, motion and intermittency of localized deformation bands; (b) simulated with crystal plasticity in the absence of DSA (standard CP model) where the complete absence of plastic instability and localized bands with a homogeneous strain rate field across the gauge section highlights the significant influence of DSA. 
Table 2: Material and simulation parameters used for crystal plasticity (CP) and dynamic strain aging (DSA).

\begin{tabular}{lll}
\hline CP model parameters & Notation & Value \\
\hline Power law exponent & $n$ & 10 \\
Reference dislocation velocity & $v_{0}$ & $5 \times 10^{-10} \mathrm{~m} / \mathrm{s}$ \\
Reference mobile dislocation density & $\rho_{0}^{m}$ & $1 \times 10^{7} \mathrm{~m}^{-2}$ \\
Latent hardening coefficients & $a_{\text {mean }}$ & 0.12 \\
& $a_{\text {col }}$ & 1.265 \\
Burgers vector magnitude & $b$ & $2.86 \times 10^{-10} \mathrm{~m}$ \\
Dislocation interaction with obstacles & $K_{m}$ & $2.4 \times 10^{4}$ \\
& $K_{f}$ & $1.4 \times 10^{4}$ \\
Hardening/softening parameters & $C_{1}$ & $2.2 \times 10^{3}$ \\
& $C_{2}$ & 80.0 \\
& $C_{3}$ & 0.0 \\
Lamé constants & $\lambda$ & $62 \mathrm{GPa}$ \\
& $\mu$ & $23 \mathrm{GPa}$ \\
\hline DSA model parameters & Notation & Value \\
\hline Diffusion time & $t_{D}$ & $10 \mathrm{sec}$ \\
Arrest term & $A_{1}$ & $1 \times 10^{-3} \mathrm{~s}^{-1}$ \\
Solute hardening constant & $f$ & $37 \mathrm{MPa}$ \\
Reference strain rate & $\dot{\epsilon_{0}}$ & $5 \times 10^{-4} \mathrm{~s}^{-1}$ \\
Applied strain rate & $\dot{\epsilon_{a}}$ & $1 \times 10^{-4} \mathrm{~s}^{-1}$ \\
Initial aging time & $t_{0}^{a}$ & $1 \mathrm{sec}$ \\
\hline Initial conditions & Notation & Value \\
\hline Initial mobile dislocation density & $\rho^{m}(0)$ & $1 \times 10^{7} \mathrm{~m}^{-2}$ \\
Initial forest dislocation density & $\rho^{f}(0)$ & $1 \times 10^{12} \mathrm{~m}^{-2}$ \\
\hline
\end{tabular}

However, we conjecture that the DSA-endorsed plastic instabilities may be orientation dependent, and may therefore have significant or negligible impact on the overall mechanical response of the sample, depending on the crystal orientation. As a consequence, DSAcontrolled nucleation, propagation, and intermittency of deformation bands might promote, leave unaffected, delay or impede crack propagation depending on the crystal orientation of the grain associated with the crack. Therefore, a study highlighting the influence of crystal orientation on DSA-triggered strain localization is now conducted.

To trigger the strain localization process, we introduce a sharp crack in the FE mesh (see Fig.3p by using the element dilution method where elements constituting the edge crack are assigned a negligible stiffness. A stiffness parameter $K$ is used for this element degradation where the modified stiffness of the element is described as

$$
\mathbf{C}_{\text {mod }}=(1-K) \mathbf{C},
$$

where $\mathbf{C}$ is the original elastic moduli tensor. Ideally, the parameter $K$ for the elements shaping the edge crack should be 1 . However, numerical stability puts a limit of $K \approx 1$, whereas $K$ is zero for the rest of the elements in the mesh. The single crystal with edge crack is discretized in $50 \times 50 \times 10$ cubic elements (each cube being filled with tetrahedral elements) in the $\mathrm{X}, \mathrm{Y}$ and $\mathrm{Z}$ directions. It is uniaxially loaded in $y$ direction with fixed displacement rate, leading initially to mode-I type fracture stress concentration fields near the crack tip. This specifically serves as the source of early plastic strain localization and we do not consider any damage and crack propagation in this study. Frequently observed orientations, specific to rolled $\mathrm{Al}-\mathrm{Cu}-\mathrm{Li}-\mathrm{Mg}$ alloys, (see Table1) are chosen for this investigation. The Euler angles listed in Table 1 are taken from a previous work [31. 


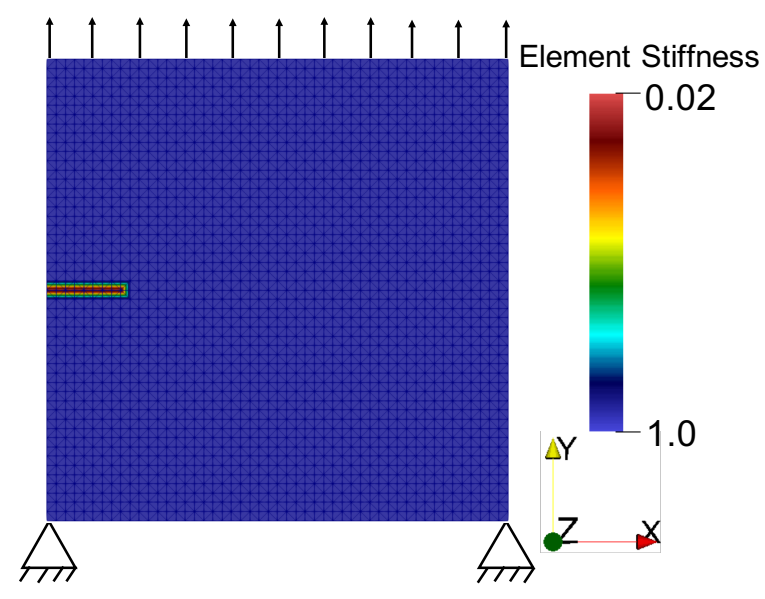

Figure 3: Single crystal with edge crack and uniaxial tension boundary condition used for FE simulations.

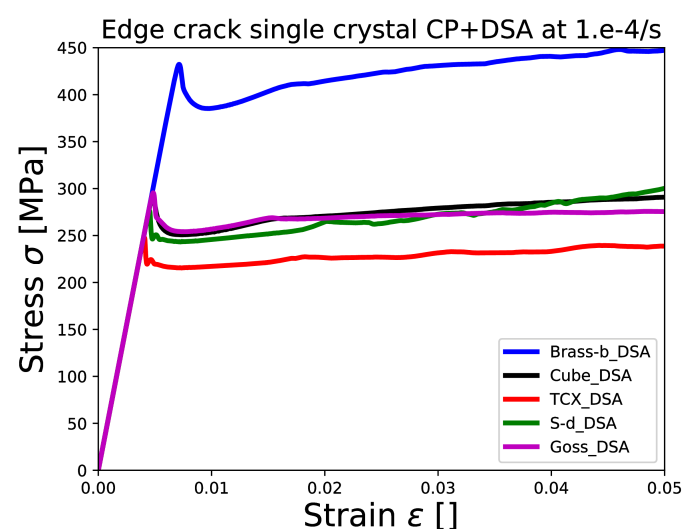

(a)

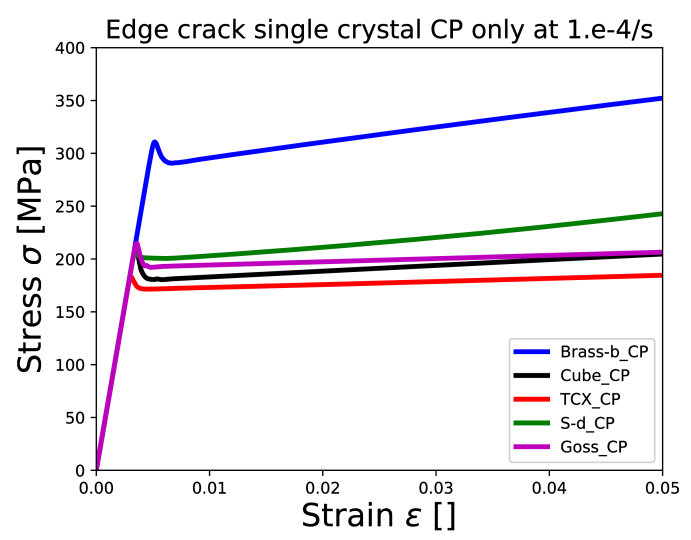

(b)

Figure 4: Orientation dependence of global deformation behavior of edge cracked single crystal loaded in fracture mode-I, (a) simulated with DSA-enabled crystal plasticity; (b) simulated with standard crystal plasticity (DSA absent). 

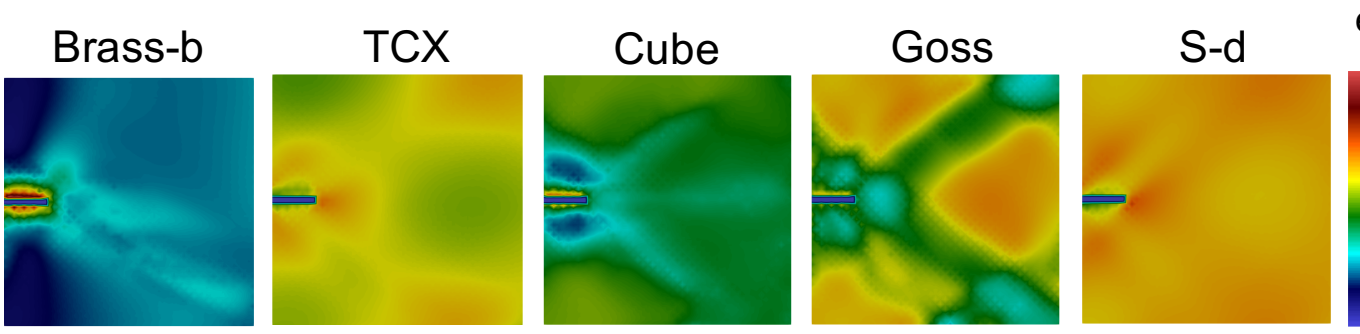

eVMp

(a)
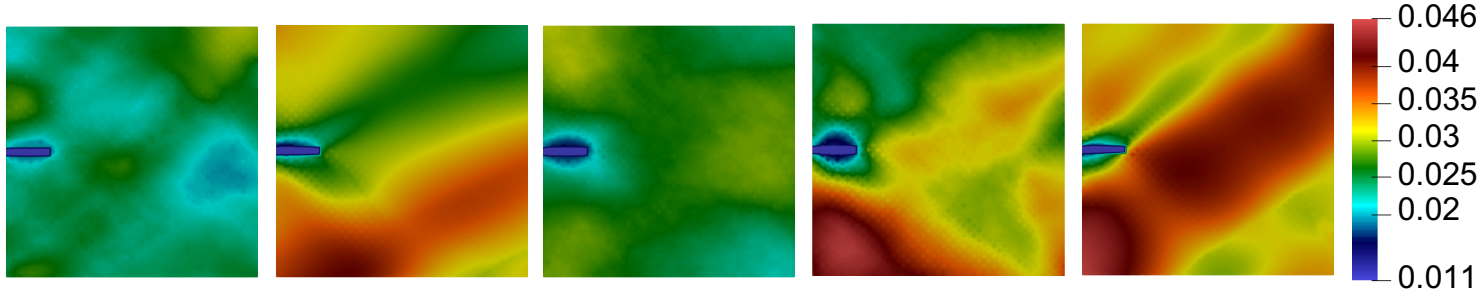

(b)
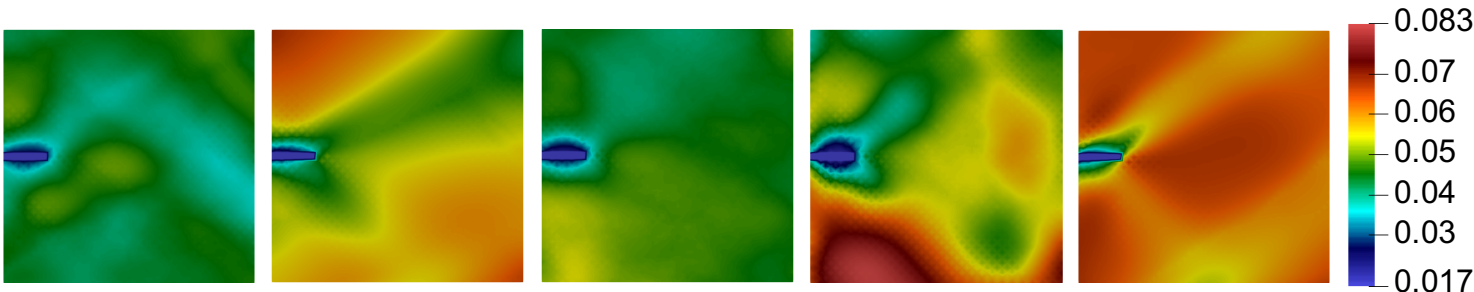

(c)

Figure 5: Equivalent von Mises plastic strain (eVMp) fields at gradually increasing global strains for different crystal orientations simulated using DSA-enabled CP model. The orientation dependence of DSA effects is manifested as divergent plastic zone extensions for the different crystal orientations under investigation, (a) eVMp at $1 \%$ global strain; (b) eVMp at $3 \%$ global strain; (c) eVMp at $5 \%$ global strain.

The influence of DSA is now examined at a local level in terms of the plastic strain fields ahead of the crack tip and their evolutions with the applied overall strain, as compared to standard CP predictions. The development of the plastic zones in the presence of DSA (see Fig.5) is observed to be less symmetric, more intense and more heterogeneous than for the plastic zones obtained with standard CP shown in Fig.6. The comparison also suggests that DSA may be beneficial in delaying fracture nucleation and growth by shifting the strain localization area away from the crack tip. In contrast, the absence of DSA results in strain lo- 

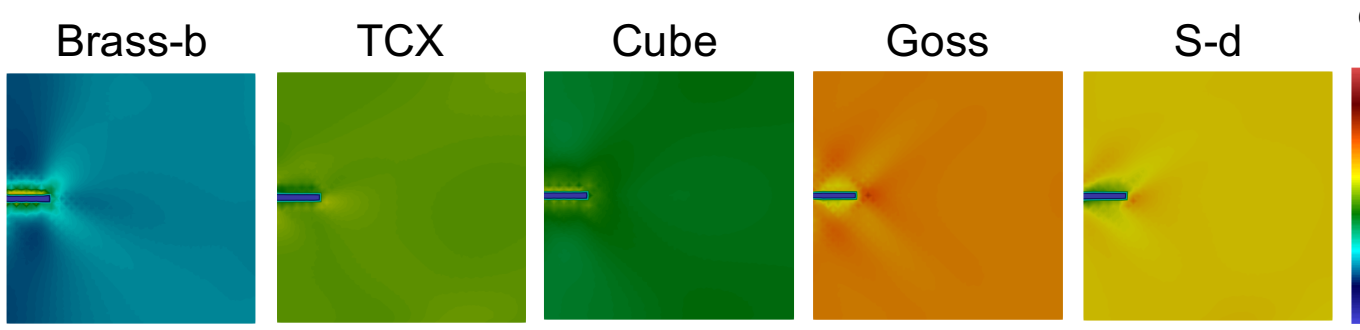

eVMp

(a)
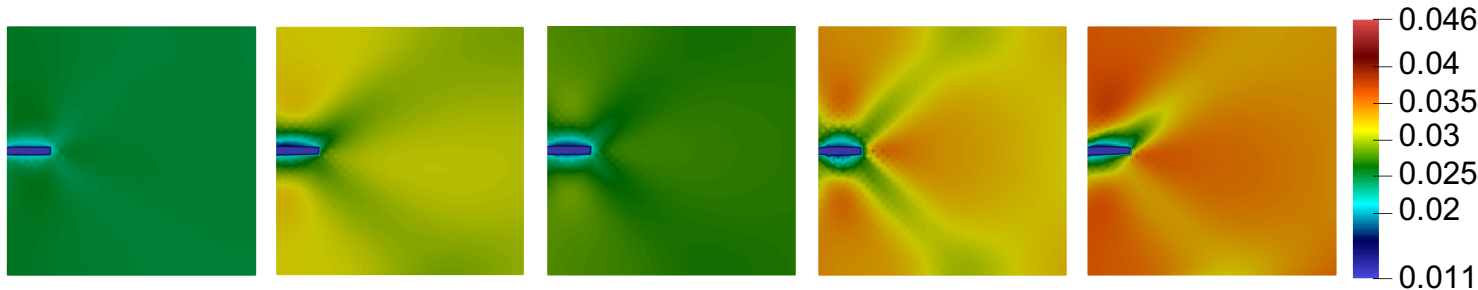

(b)
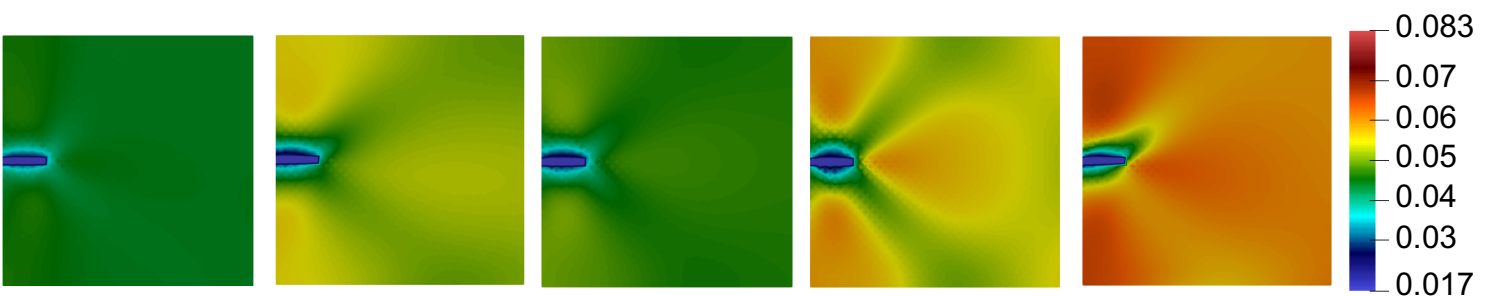

(c)

Figure 6: Equivalent von Mises plastic strain (eVMp) fields at gradually increasing global strains for different crystal orientations simulated with standard CP (DSA module absent), (a) eVMp at $1 \%$ global strain; (b) eVMp at $3 \%$ global strain; (c) eVMp at $5 \%$ global strain. 


\subsection{Edge cracked multi-layered polycrystal: effect of orientation couples}

In the series of efforts made to generate a texture that is resistant to strain localization, investigating the contribution of individual orientations is necessary but not sufficient. Grain interactions may play a significant role, and the deformation behavior for a particular crystal orientation may substantially differ from that obtained in the presence of neighboring grains with different orientations. Therefore, we now conduct investigations using combinations of orientation couples.

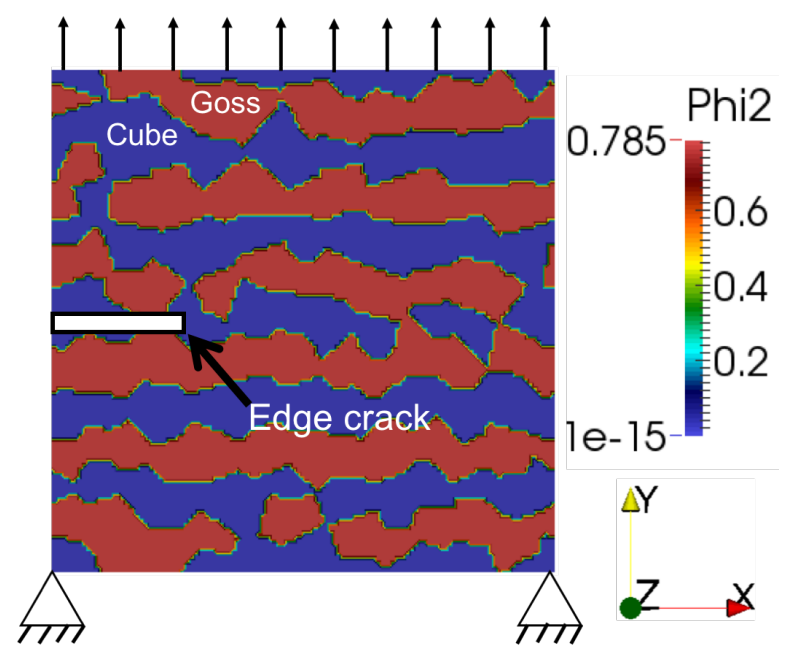

Figure 7: Edge-cracked multi-layered polycrystal with embedded orientation couples (here Cube-Goss) and uniaxial tension boundary conditions.

All of the $C_{2}^{5}=10$ possible orientation couples obtained by considering the five frequently observed orientations: Brass-b-Goss, Cube-TCX, Goss-S-d,..etc., were simulated in uniaxial tension, both in presence and in absence of DSA. As before, the simulations performed with the CP only model (without DSA) are used as references highlighting the influence of DSA on the local fields and macroscopic stress-strain behavior. As shown in Fig.77, a multi-layered FE mesh inspired from the experimental observation of rolled microstructures of $\mathrm{Al}-\mathrm{Cu}-\mathrm{Li}-$ $\mathrm{Mg}$ alloys is adopted to investigate the interaction of orientation couples.

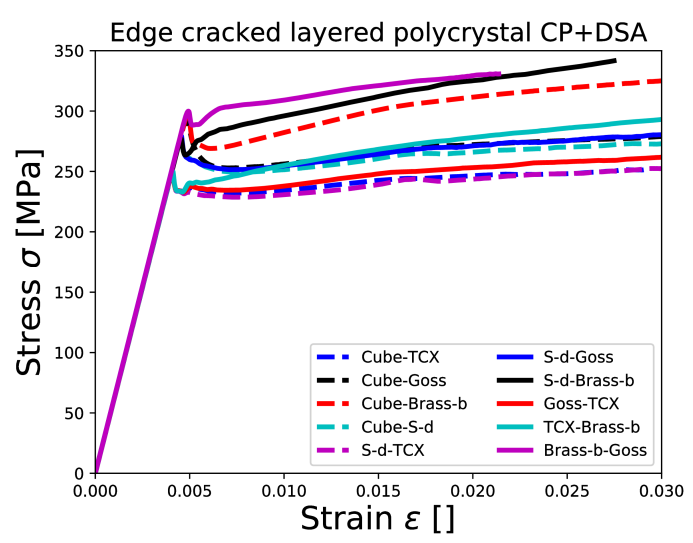

(a)

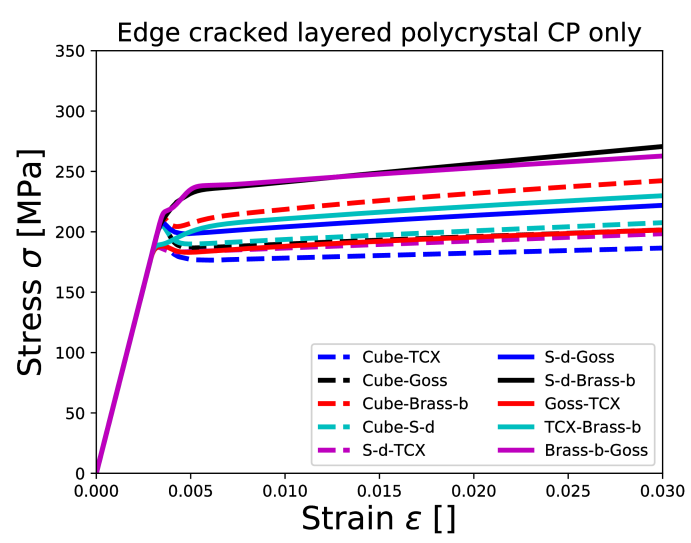

(b)

Figure 8: Averaged flow stress of edge cracked layered orientation couples loaded in fracture mode-I, (a) simulated with DSA enabled crystal plasticity; (b) simulated with standard crystal plasticity (DSA absent). 
Similar to single crystal results, the layered polycrystalline morphology exhibits prominent differences in the macroscopic stress-strain curves obtained from the DSA-enabled CP model as compared to standard CP calculations (see Fig.8). As already found, higher flow stresses and larger yield drops obtained for the DSA-enabled model can be associated with the solute stress and first solute-dislocation breakaway event, respectively. The macroscopic stress-strain curves obtained from DSA-enabled CP can be relatively divided in two categories: orientation couples containing Brass-b and others excluding Brass-b. Indeed, it is observed that coupling any orientation with the Brass-b orientation results in a 50 to $100 \mathrm{MPa}$ boost in the macroscopic flow stress, with the notable exception of TCX-Brass-b. The influence of DSA is also evident from small but crucial changes in the relative flow stresses for different orientation couples as compared to results obtained using standard CP.
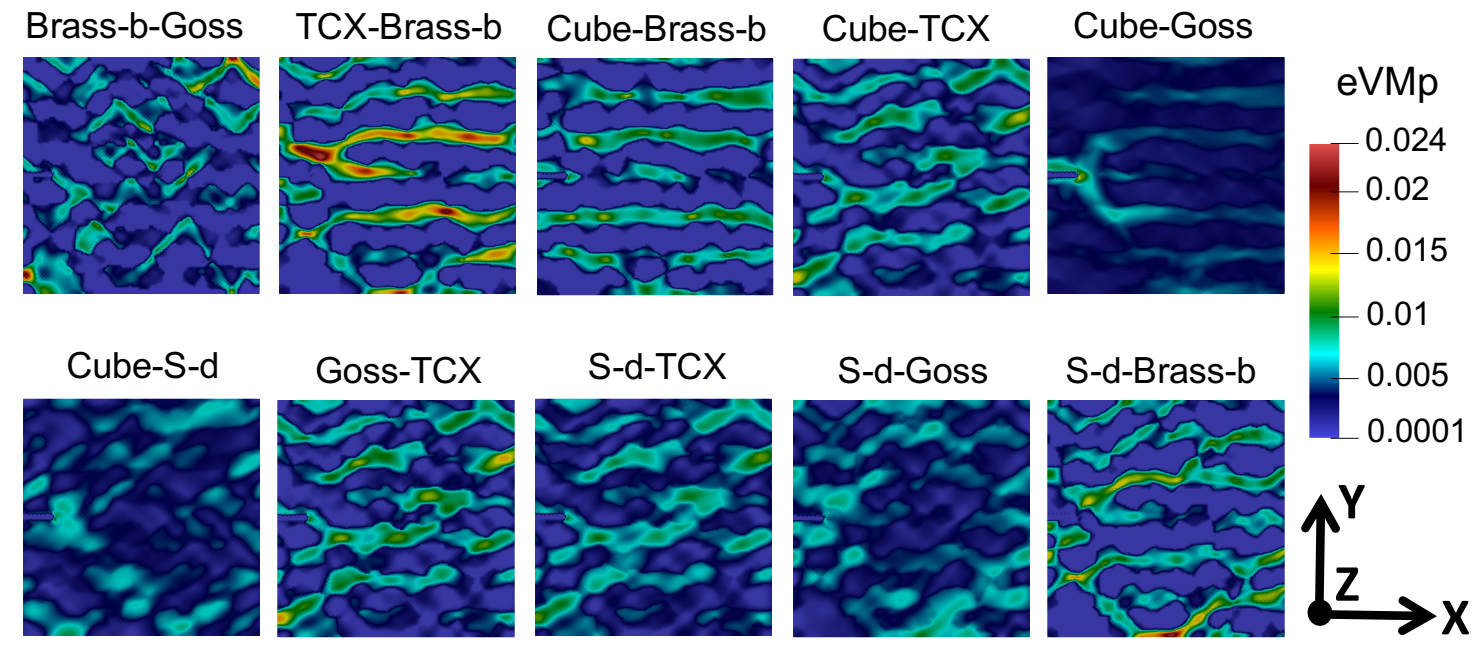

(a)
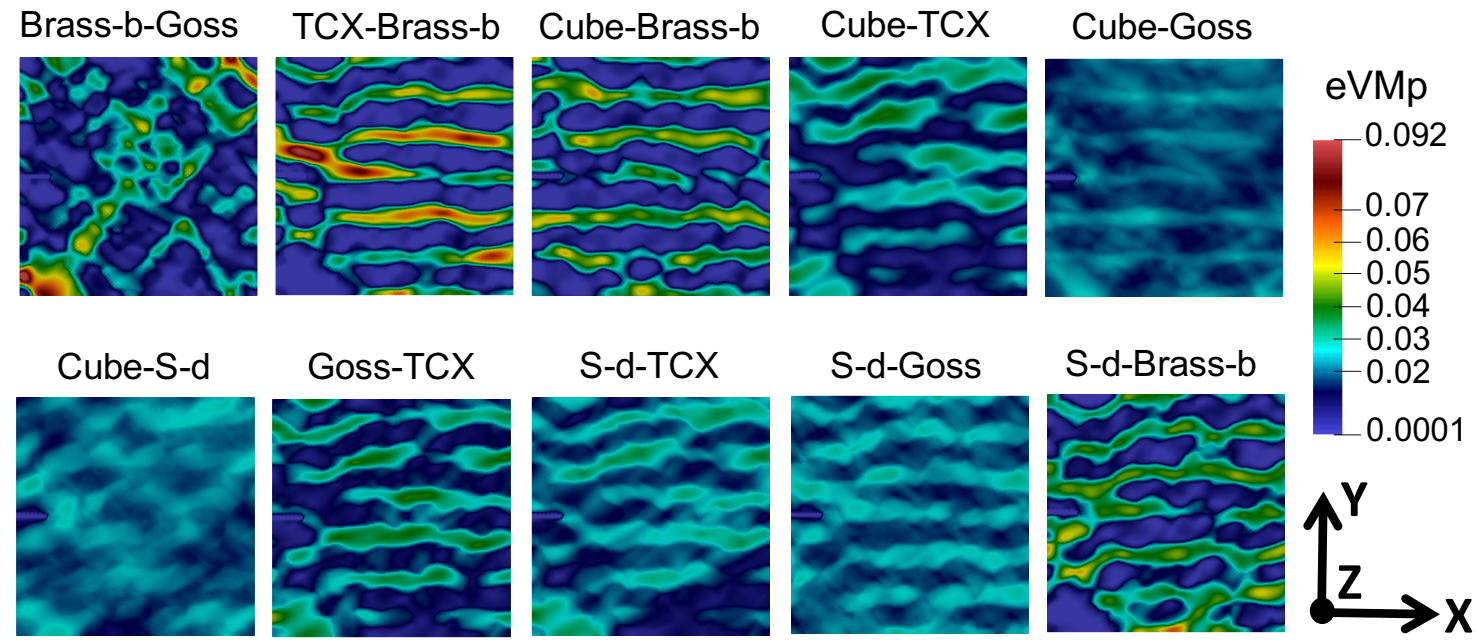

(b)

Figure 9: Equivalent plastic strain (eVMp) fields at gradually increasing global strains for different orientation couples. DSA plays a significant role in changing the behavior of a particular orientation in the presence of other crystal orientations, (a) eVMp at $0.6 \%$ global strain; (b) eVMp at $2 \%$ global strain.

The analysis of the predicted plastic strain fields is now conducted to investigate the joint influences of grain orientation couples and DSA on strain localization leading to failure. To this end, Fig.9 presents the equivalent plastic strain (eVMp) fields predicted for the ten orientation couples at two distinct strain levels: $0.6 \%$, which is close to the elasto-plastic 
transition, and $2 \%$, that is in the hardening regime. For most of the orientation couples, the initiation of the plastic zone swiftly migrates away from the crack tip in the presence of DSA, which may have again a stabilizing influence on incoming crack propagation, and the high strain zones are found to be rather independent of the edge crack location. The plastic strain fields for the various orientation couples can be broadly divided into two categories: orientation couples exhibiting highly heterogeneous strain distributions, and orientation couples displaying rather homogeneous strain distributions (see Fig.9(b)). Most notably and in strong contrast with the beneficial properties of the Brass-b orientation for single crystal simulations, nearly all the orientations coupled with Brass-b now demonstrate strong strain localization and heterogeneous plastic strain fields as compared to other couplings, a property that can be detrimental with respect to strain localization leading to fracture. In particular, TCX-Brass-b shows the strongest strain localization trend, which can be related to its relatively low hardening rate in Fig, 8 . Such a result highlights the importance of considering the effects of grain neighborhood and grain-to-grain interactions. On the contrary, mutual couplings of S-d, Goss and Cube orientations promote a rather homogeneous plastic strain distribution, and therefore could well be better candidates while choosing orientation distributions less prone to strain localization. Note that the simulations predict a strong anisotropy of plastic deformation in grains, with possible high contrast between grains, in particular for Brass-b/S-d couples, which is in good agreement with available experimental and modeling data 32 34].

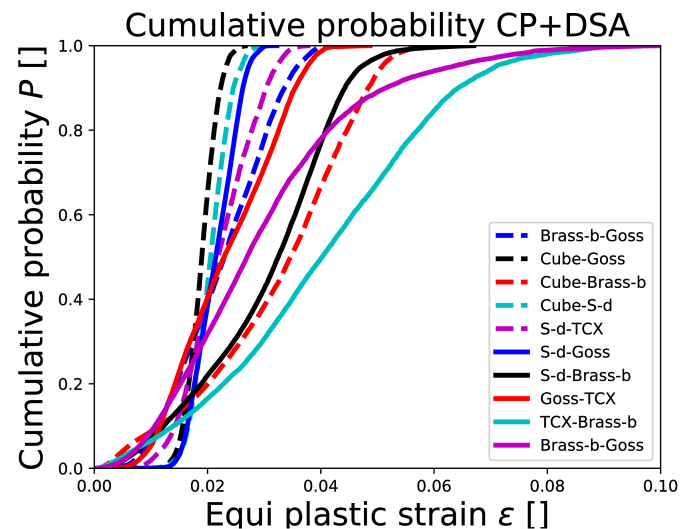

(a)

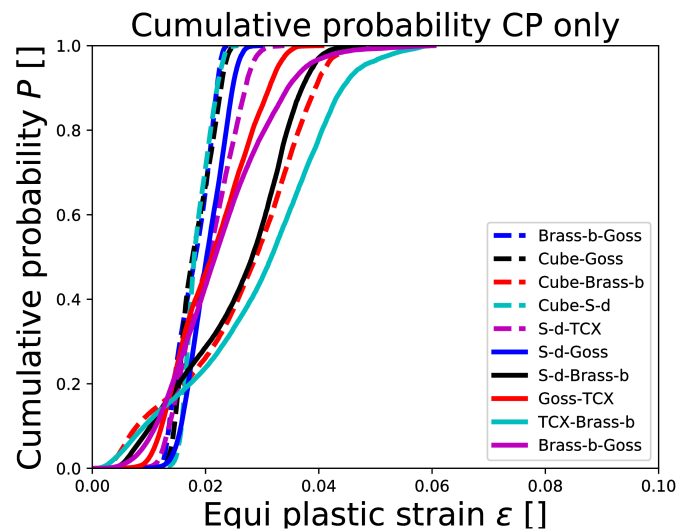

(b)

Figure 10: Cumulative probability distributions of the equivalent plastic strain at 0.02 average tensile strain for edge cracked layered orientation couples loaded in fracture mode-I, (a) simulated with DSA-enabled CP; (b) simulated with standard CP (DSA absent).

A more synthetic presentation of the above-discussed strong vs. weak strain localization patterns pertaining to different orientation couples is shown in Fig. 10 where the cumulative probability of equivalent plastic strain (eVMp) is computed and plotted at $2 \%$ global strain for all orientation couples. To interpret these plots, note that a narrow cumulative probability of plastic strain suggests a small scatter of plastic strain throughout the sample, and hence a rather homogeneous plastic strain field. As compared to standard CP results, a larger spread in the cumulative probability obtained from DSA-enabled CP is a direct indication of DSA triggered stronger heterogeneity in eVMp (see Fig.10(a) and 10(b)). In addition, the cumulative probability spread is found to be larger in the presence of the Brass-b orientation, as compared to mutual couplings of the S-d, Goss and Cube orientations, which again points to a stronger strain heterogeneity. In particular, the TCX-Brass-b orientation couple exhibits the larger spread and higher strain heterogeneity, with local strains nearly reaching 0.1 at a macroscopic strain of 0.02 . 


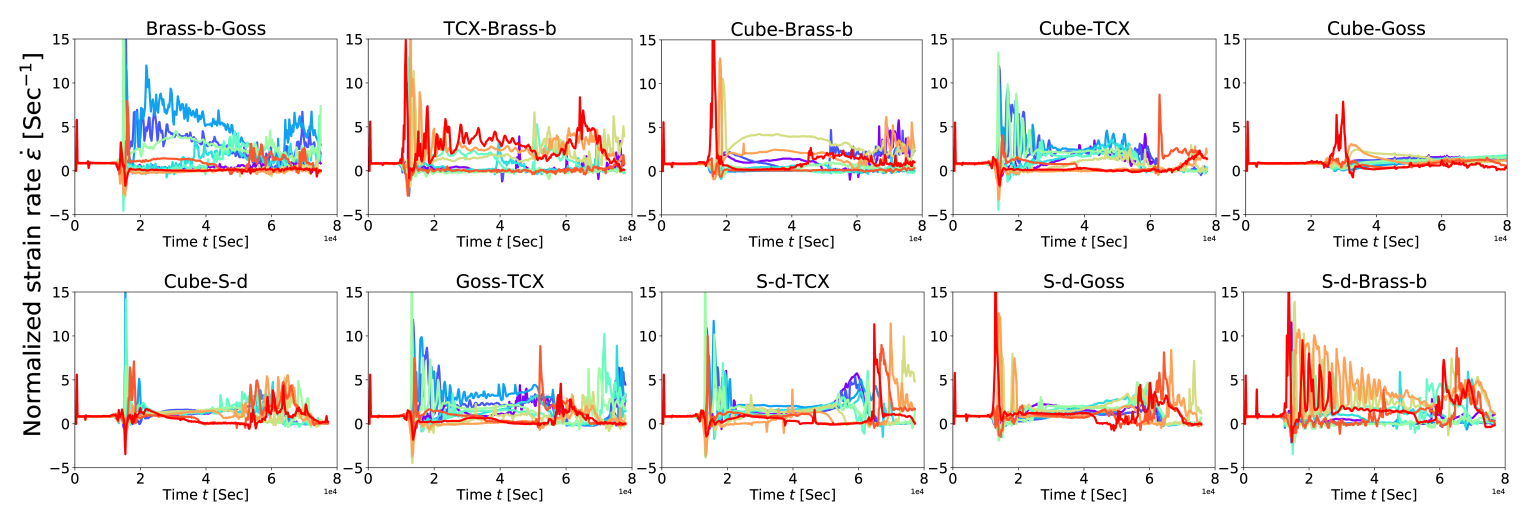

(a)

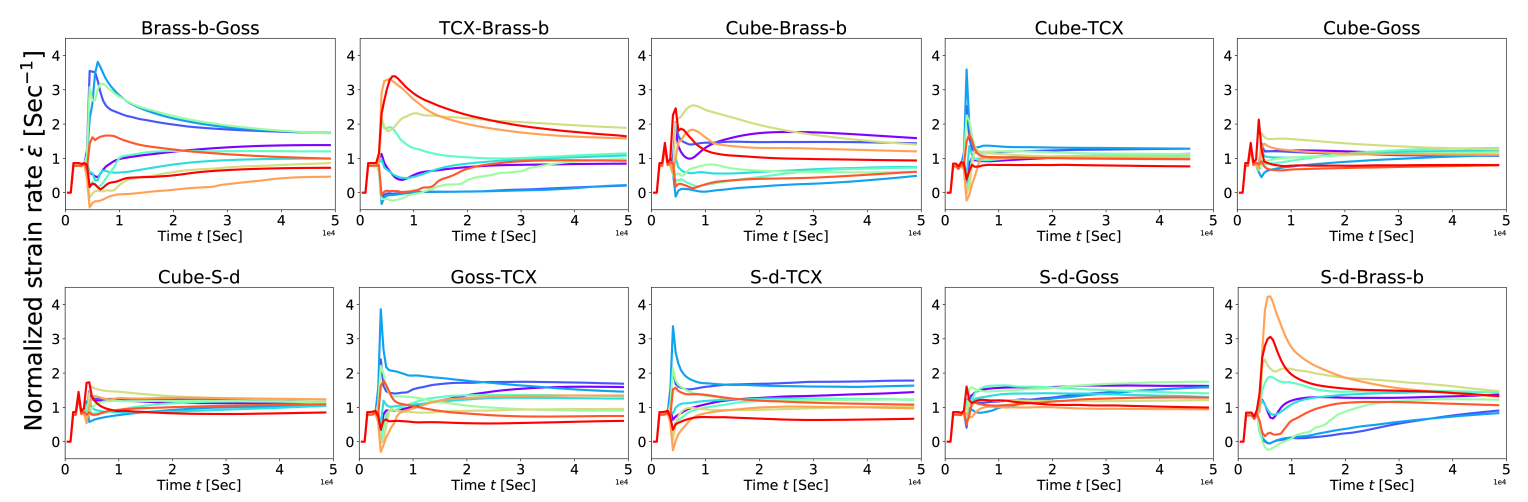

(b)

Figure 11: Time evolution of strain rate for randomly chosen nodes in the mesh, (a) simulated with DSA enabled crystal plasticity; (b) simulated with standard crystal plasticity (DSA absent).

Finally, the intermittency of the equivalent strain rate field $\dot{\epsilon}_{\text {eq }}$ is examined in relation with its heterogeneity by plotting this quantity in Fig.11. normalized by the overall applied strain rate $\dot{\epsilon}_{a}$, at ten different (randomly chosen) locations in the sample. In comparison to smooth strain rate variations obtained from standard CP and shown in Fig. 11(b), DSA-enabled CP clearly yields a recurrence of sharp peaks, i.e. a highly intermittent behavior often associated with the PLC effect (Fig.11(a)]. Further, the heterogeneity apparent in Fig.11(b), which simply derives from location and orientation differences, is found to be amplified by DSA in Fig.11(a), and intermittency usually appears to be highest at locations where the equivalent strain rate is the largest. Of course, the calculations shown in Fig.11 confirm that the intermittency observed in the DSA-enabled CP simulations is a direct consequence of the dislocation-solute interactions, by which every peak in the strain rate spatiotemporal field is associated with a particular set of pinning and breakaway events.

\section{Conclusions}

The primary findings of the presented investigation can be summarized as follows:

1. A successful slip system-based implementation of a DSA constitutive model, coupling the dynamics of mobile and sessile dislocation densities in standard small scale crystal plasticity, allows accurately mimicking the experimental observations for dilute $\mathrm{Al}-\mathrm{Cu}-$ $\mathrm{Li}-\mathrm{Mg}$ alloys. We are able to capture both macroscopic serrated stress-strain curves and plastic strain and strain rate fields involving recurrent nucleation and propagation of strain localization bands on various slip systems, as observed in experiments. In contrast, a smooth flow stress and complete absence of plastic instabilities is seen for the standard CP model (DSA module absent). 
2. Simulations of edge cracked single crystals loaded in fracture mode-I demonstrated a strong orientation dependence of the destabilizing effects of DSA. The development of a plastic strain localization area is observed to be quite localized for orientations such as Goss, S-d and TCX, whereas the Brass-b and Cube orientations favor a relatively homogeneous plastic strain field.

3. The results obtained from investigating orientation couples highlight the strong influence of the latter on the destabilizing effects of DSA. Nearly all the orientations in the presence of Brass-b demonstrate stronger strain localization patterns and more heterogeneous plastic strain fields than the mutual couplings of S-d, Goss and Cube. The latter are therefore found to be beneficial in terms of homogeneous strain distribution. The rather opposite influences of the Brass-b orientation, paradoxically seen as a stabilizing factor in single crystal simulations and a destabilizing one when neighboring grains are taken into account, highlight the importance of grain neighborhood as well as grain-to-grain interactions in microstructures.

It is important to note that above mentioned outcomes are true for solicitation in the transverse directions and propagation in the rolling direction. We expect a significant changes in conclusion for traction in the rolling direction and propagation in the transverse direction, which could be a potential outlook for the present work. Further steps in this research involve the simulation of a more realistic Kahn tear test with a sample containing a large number of grains, such as to investigate in more details the role of texture and grain-to-grain interactions in the early localization phenomena. To this end, a numerical spectral method using Fast Fourier transforms (FFT) algorithms [42, 43] will be considered. Spectral CP-FFT methods are computationally much more efficient than the CP-FEA methods, which allows dealing with much larger polycrystalline samples, with foreseeable benefits in the prediction of textures at large strains. The only inherent rigidity attached to spectral methods, i.e. need of periodic boundary conditions can be averted by using buffer zones at the sample boundaries. Further, in AA-2198-T8 alloys, the beneficial role of nanosize T1 precipitates in terms of strength and strain homogenization will be investigated [16 19]. It was recently demonstrated that certainly such platelet precipitates, which form mostly on dislocation lines on $\{111\}$ slip planes during an artificial heat treatment applied to T3 alloys, have a heterogeneous spatial distribution and cannot be sheared twice by dislocation lines at the same location, which limits dislocation avalanches. While early strain localization is still observed in the Kahn tear tests of AA-2198-T8 alloys [13, the competition between T1 precipitates and dynamic strain aging on strain localization is thought to be important and a constitutive law accounting for precipitates will be developed, which will allow refining microstructure design in view of limiting strain localization phenomena.

\section{Acknowledgments}

Authors would like to acknowledge the support and funding from C-TEC Constellium Technology Center, by the French State through the National Research Agency (ANR) under the program Investment in the future (LabEx DAMAS referenced as ANR-11-LABX-000801) and from the Région Grand-Est.

\section{Declaration of interest}

None

\section{References}

[1] T. S. Srivatsan, T. Hoff, S. Sriram, A. Prakash, The effect of strain rate on flow stress, strength and ductility of an Al-Li-Mg alloy, Journal of Materials Science Letters 9 (3) (1990) 297-300. doi:10.1007/BF00725830. 
[2] T. Warner, Recently-developed aluminium solutions for aerospace applications, in: Aluminium Alloys 2006 - ICAA10, Vol. 519 of Materials Science Forum, Trans Tech Publications, 2006, pp. 1271-1278. doi:10.4028/www.scientific.net/MSF.519-521.1271.

[3] J. Liu, Advanced Aluminium and Hybrid Aerostructures for Future Aircraft, Materials Science Forum 519-521 (2006) 1233-1238. doi:10.4028/www.scientific.net/MSF. 519-521.1233.

URL http://www.scientific.net/MSF.519-521.1233

[4] R. Wanhill, Chapter 15 - aerospace applications of aluminum-lithium alloys, in: N. E. Prasad, A. A. Gokhale, R. Wanhill (Eds.), Aluminum-lithium Alloys, Butterworth-Heinemann, Boston, 2014, pp. 503 - 535. doi:https: //doi.org/10.1016/B978-0-12-401698-9.00015-X. URL http://wWw.sciencedirect.com/science/article/pii/ B978012401698900015X

[5] R. J. Rioja, J. Liu, The evolution of Al-Li base products for aerospace and space applications, Metallurgical and Materials Transactions A: Physical Metallurgy and Materials Science 43 (9) (2012) 3325-3337. doi:10.1007/s11661-012-1155-z.

[6] N. D. Alexopoulos, E. Migklis, A. Stylianos, D. P. Myriounis, Fatigue behavior of the aeronautical Al-Li (2198) aluminum alloy under constant amplitude loading, International Journal of Fatigue 56 (2013) 95-105. doi:10.1016/j.ijfatigue.2013.07.009. URL http://dx.doi.org/10.1016/j.ijfatigue.2013.07.009

[7] A. Steuwer, M. Dumont, J. Altenkirch, S. Birosca, A. Deschamps, P. B. Prangnell, P. J. Withers, A combined approach to microstructure mapping of an Al-Li AA2199 friction stir weld, Acta Materialia 59 (8) (2011) 3002-3011. doi:10.1016/j .actamat.2011.01. 040

URL http://dx.doi.org/10.1016/j.actamat.2011.01.040

[8] S. Choi, F. Barlat, Prediction of macroscopic anisotropy in rolled aluminum-lithium sheet, Scripta Materialia 41 (9). doi:10.1016/S1359-6462(99)00241-9.

[9] Y. Lin, Z. Zheng, S. Li, X. Kong, Y. Han, Microstructures and properties of 2099 Al-Li alloy, Materials Characterization 84 (2013) 88-99. doi:10.1016/j.matchar.2013.07. 015. URL http://dx.doi.org/10.1016/j.matchar.2013.07.015

[10] A. Bois-Brochu, C. Blais, F. A. T. Goma, D. Larouche, J. Boselli, M. Brochu, Characterization of Al-Li 2099 extrusions and the influence of fiber texture on the anisotropy of static mechanical properties, Materials Science and Engineering A 597 (2014) 62-69. doi:10.1016/j.msea.2013.12.060.

URL http://dx.doi.org/10.1016/j.msea.2013.12.060

[11] A. A. Csontos, E. A. Starke, The effect of inhomogeneous plastic deformation on the ductility and fracture behavior of age hardenable aluminum alloys, International Journal of Plasticity 21 (6) (2005) 1097-1118. doi:10.1016/j.ijplas.2004.03.003.

[12] T. F. Morgeneyer, J. Besson, Flat to slant ductile fracture transition: Tomography examination and simulations using shear-controlled void nucleation, Scripta Materialia 65 (11) (2011) 1002-1005. doi:10.1016/j.scriptamat.2011.09.004.

URL http://dx.doi.org/10.1016/j.scriptamat.2011.09.004

[13] T. F. Morgeneyer, T. Taillandier-Thomas, L. Helfen, T. Baumbach, I. Sinclair, S. Roux, F. Hild, In situ 3-D observation of early strain localization during failure of thin $\mathrm{Al}$ alloy (2198) sheet, Acta Materialia 69 (2014) 78-91. doi:10.1016/j.actamat.2014.01.033. 
[14] M. R. Joyce, M. J. Starink, I. Sinclair, Assessment of mixed mode loading on macroscopic fatigue crack paths in thick section Al-Cu-Li alloy plate, Materials and Design 93 (2016) 379-387. doi:10.1016/j.matdes.2015.12.116. URL http://dx.doi.org/10.1016/j.matdes.2015.12.116

[15] A. Abd El-Aty, Y. Xu, X. Guo, S. H. Zhang, Y. Ma, D. Chen, Strengthening mechanisms, deformation behavior, and anisotropic mechanical properties of Al-Li alloys: A review, Journal of Advanced Research 10 (2018) 49-67. doi:10.1016/j.jare.2017.12.004. URL https://doi.org/10.1016/j.jare.2017.12.004

[16] P. Donnadieu, Y. Shao, F. D. Geuser, G. Botton, S. Lazar, M. Cheynet, M. de Boissieu, A. Deschamps, Atomic structure of t1 precipitates in al-li-cu alloys revisited with haadfstem imaging and small-angle x-ray scattering, Acta Materialia 59 (2) (2011) $462-472$. doi:https://doi.org/10.1016/j.actamat.2010.09.044 URL http://www.sciencedirect.com/science/article/pii/S135964541000621X

[17] A. Deschamps, B. Decreus, F. D. Geuser, T. Dorin, M. Weyland, The influence of precipitation on plastic deformation of al-cu-li alloys, Acta Materialia 61 (11) (2013) 4010 - 4021. doi:https://doi.org/10.1016/j.actamat.2013.03.015. URL http://www.sciencedirect.com/science/article/pii/S1359645413002255

[18] V. Araullo-Peters, B. Gault, F. de Geuser, A. Deschamps, J. M. Cairney, Microstructural evolution during ageing of al-cu-li-x alloys, Acta Materialia 66 (2014) 199 - 208. doi: https://doi.org/10.1016/j.actamat.2013.12.001.

URL http://www.sciencedirect.com/science/article/pii/S1359645413009361

[19] T. Dorin, A. Deschamps, F. D. Geuser, F. Robaut, Impact of grain microstructure on the heterogeneity of precipitation strengthening in an al-li-cu alloy, Materials Science and Engineering: A 627 (2015) 51-55. doi:https://doi.org/10.1016/j.msea.2014. 12.073. URL http://www.sciencedirect.com/science/article/pii/S0921509314015731

[20] D. Delafosse, G. Lapasset, L. Kubin, Dynamic strain ageing and crack propagation in the 2091 Al-Li alloy, Scripta Metallurgica et Materialia 29 (11) (1993) $1379-1384$. doi:https://doi.org/10.1016/0956-716X(93)90323-K. URL http://wwW.sciencedirect.com/science/article/pii/0956716X9390323K

[21] L. Fournier, D. Delafosse, T. Magnin, Oxidation induced intergranular cracking and Portevin-Le Chatelier effect in nickel base superalloy 718, Materials Science and Engineering A 316 (1-2) (2001) 166-173. doi:10.1016/S0921-5093(01)01224-2.

[22] H. Wang, C. Berdin, M. Mazière, S. Forest, C. Prioul, A. Parrot, P. Le-Delliou, PortevinLe Chatelier (PLC) instabilities and slant fracture in C-Mn steel round tensile specimens, Scripta Materialia 64 (5) (2011) 430-433. doi:10.1016/j.scriptamat.2010.11.005.

[23] A. R. Das, T. Chowdhury, S. Sivaprasad, H. N. Bar, N. Narasaiah, S. Tarafder, Influence of dynamic strain ageing on fracture behaviour and stretch zone formation of a reactor pressure vessel steel, International Journal of Fracture 202 (1) (2016) 79-91. doi: $10.1007 / \mathrm{s} 10704-016-0134-6$.

[24] V. Garat, J. M. Cloue, D. Poquillon, E. Andrieu, Influence of Portevin-Le Chatelier effect on rupture mode of alloy 718 specimens, Journal of Nuclear Materials 375 (1) (2008) 95-101. doi:10.1016/j.jnucmat.2007.10.009.

[25] J. Chen, Y. Madi, T. F. Morgeneyer, J. Besson, Plastic flow and ductile rupture of a 2198 Al-Cu-Li aluminum alloy, Computational Materials Science 50 (4) (2011) 13651371. doi:10.1016/j.commatsci.2010.06.029.

URL http://dx.doi.org/10.1016/j.commatsci.2010.06.029 
[26] S. C. Ren, G. Rousselier, T. F. Morgeneyer, M. Mazière, S. Forest, Numerical investigation of dynamic strain ageing and slant ductile fracture in a notched specimen and comparison with synchrotron tomography 3D-DVC, Procedia Structural Integrity 2 (2016) 3385-3392. doi:10.1016/j.prostr.2016.06.422.

URL http://linkinghub.elsevier.com/retrieve/pii/S2452321616304413

[27] A. F. Buljac, L. Helfen, F. Hild, T. F. Morgeneyer, Early strain localization in strong work hardening aluminum alloy (2198 T3): 3D laminography and DVC measurement, in: L. Lamberti, M.-T. Lin, C. Furlong, C. Sciammarella (Eds.), Advancement of optical methods in experimental mechanics, volume 3, Proceedings of the 2017 Annual Conference on Experimental and Applied Mechanics, Springer, 2018, pp. 15-17.

URL https://hal-mines-paristech .archives-ouvertes.fr/hal-01634158

[28] S. Gupta, A. J. Beaudoin, J. Chevy, Strain rate jump induced negative strain rate sensitivity (NSRS) in aluminum alloy 2024: Experiments and constitutive modeling, Materials Science and Engineering: A 683 (September 2016) (2017) 143-152. doi: 10.1016/j.msea.2016.12.010.

URL http://linkinghub.elsevier.com/retrieve/pii/S0921509316314927

[29] S. C. Ren, T. F. Morgeneyer, M. Mazière, S. Forest, G. Rousselier, Portevin-le chatelier effect triggered by complex loading paths in an al-cu aluminium alloy, Philosophical Magazine 99 (6) (2019) 659-678. arXiv:https://doi.org/10.1080/14786435.2018. 1550296, doi:10.1080/14786435.2018.1550296.

URL https://doi.org/10.1080/14786435.2018.1550296

[30] T. F. Morgeneyer, T. Taillandier-Thomas, A. Buljac, L. Helfen, F. Hild, On strain and damage interactions during tearing: 3D in situ measurements and simulations for a ductile alloy (AA2139-T3), Journal of the Mechanics and Physics of Solids 96 (2016) 550-571. doi:10.1016/j.jmps.2016.07.012.

URL http://dx.doi.org/10.1016/j.jmps.2016.07.012

[31] V. Taupin, J. Chevy, C. Fressengeas, Effects of grain-to-grain interactions on shear strain localization in Al-Cu-Li rolled sheets, International Journal of Solids and Structures 99 (2016) 71-81. doi:10.1016/j.ijsolstr.2016.07.023. URL http://dx.doi.org/10.1016/j.ijsolstr.2016.07.023

[32] A. Beaudoin, M. Obstalecki, W. Tayon, M. Hernquist, R. Mudrock, P. Kenesei, U. Lienert, In situ assessment of lattice strain in an al-li alloy, Acta Materialia 61 (9) (2013) 3456 - 3464. doi:https://doi.org/10.1016/j.actamat.2013.02.037. URL http://www.sciencedirect.com/science/article/pii/S1359645413001596

[33] M. Messner, A. Beaudoin, R. Dodds, An interface compatibility/equilibrium mechanism for delamination fracture in aluminum-lithium alloys, Engineering Fracture Mechanics 133 (2015) 70 - 84. doi:https://doi.org/10.1016/j.engfracmech.2014.11.003. URL http://www.sciencedirect.com/science/article/pii/S0013794414003658

[34] M. C. Messner, A. J. Beaudoin, R. H. Dodds, Jr., Mesoscopic modeling of crack arrestor delamination in $\mathrm{Al}-\mathrm{Li}$ : primary crack shielding and T-stress effect, INTERNATIONAL JOURNAL OF FRACTURE 188 (2) (2014) 229-249. doi:\{10.1007/ s10704-014-9957-1\}.

[35] T. Richeton, G. Wang, C. Fressengeas, Continuity constraints at interfaces and their consequences on the work hardening of metal-matrix composites, Journal of the Mechanics and Physics of Solids 59 (10) (2011) 2023 - 2043. doi:https://doi.org/10. 1016/j.jmps.2011.07.006.

URL http://www.sciencedirect.com/science/article/pii/S0022509611001438 
[36] P. Franciosi, M. Berveiller, A. Zaoui, Latent hardening in copper and aluminium single crystals, Acta Metallurgica 28 (3) (1980) 273-283. doi:https://doi.org/10.1016/ 0001-6160(80)90162-5

URL http://wWw.sciencedirect.com/science/article/pii/0001616080901625

[37] C. Fressengeas, A. J. Beaudoin, M. Lebyodkin, L. P. Kubin, Y. Estrin, Dynamic strain aging: A coupled dislocation-Solute dynamic model, Materials Science and Engineering A 400-401 (1-2 SUPPL.) (2005) 226-230. doi:10.1016/j.msea.2005.02.073.

[38] S. Kok, M. Bharathi, A. Beaudoin, C. Fressengeas, G. Ananthakrishna, L. Kubin, M. Lebyodkin, Spatial coupling in jerky flow using polycrystal plasticity, Acta Materialia 51 (13) (2003) 3651 - 3662. doi :https://doi .org/10.1016/S1359-6454(03)00114-9. URL http://www.sciencedirect.com/science/article/pii/S1359645403001149

[39] H. F., New development in freefem++, J. Num. Math. 20 (2012) 251-266.

[40] A. Acharya, A model of crystal plasticity based on the theory of continuously distributed dislocations, Journal of the Mechanics and Physics of Solids 49 (4) (2001) 761-784. doi:10.1016/S0022-5096(00)00060-0.

[41] A. Marais, M. Mazière, S. Forest, A. Parrot, P. L. Delliou, Identification of a strain-aging model accounting for lüders behavior in a c-mn steel, Philosophical Magazine 92 (2012) 3589-3617. doi:10.1080/14786435.2012.699687.

[42] K. S. Djaka, V. Taupin, S. Berbenni, C. Fressengeas, A numerical spectral approach to solve the dislocation density transport equation, Modelling and Simulation in Materials Science and Engineering 23 (6) (2015) 065008. doi:10.1088/0965-0393/23/6/065008.

[43] K. S. Djaka, A. Villani, V. Taupin, L. Capolungo, S. Berbenni, Field dislocation mechanics for heterogeneous elastic materials: A numerical spectral approach, Computer Methods in Applied Mechanics and Engineering 315 (2017) 921 - 942. doi:https: //doi.org/10.1016/j.cma.2016.11.036.

URL http://wWw.sciencedirect.com/science/article/pii/S0045782516304741 